九州大学学術情報リポジトリ

Kyushu University Institutional Repository

\title{
Development of Cacao Pod Crushing Machine
}

May Rose B. Osoteo

Caraga State University

Lois Y. Pajaron

Caraga State University

Arfelyn A. Paque

Caraga State University

https://doi.org/10.5109/4738580

出版情報: Proceedings of International Exchange and Innovation Conference on Engineering \& Sciences (IEICES). 7, pp. 143-148，2021-10-21. 九州大学大学院総合理工学府 バージョン：

権利関係: 


\title{
Development of Cacao Pod Crushing Machine
}

\author{
May Rose B. Osoteo ${ }^{1 *}$, Lois Y. Pajaron ${ }^{1}$, Arfelyn A. Paque ${ }^{1}$ \\ ${ }^{1}$ Caraga State University \\ *Corresponding author email: msboston@carsu.edu.ph
}

\begin{abstract}
Fermented dry cocoa beans are the primary raw material for chocolate production. Cocoa beans are the seeds of the fruits of the cocoa tree. In the Philippines, the manual method of splitting and bean removal from pods is widely used in small-scale farms. And the existence of mechanical cacao pod splitting machines were not available in small or even in some bigger farms. Thus, this study aimed to develop a cacao pod crushing machine to mechanize these processes and improve the cacao production in the country. The machine was composed of a hopper and a sieve that separates the beans from the pods. The machine's performance was evaluated using analysis of variance and t-test. The results showed significant differences in beans separation with $34 \%$ output capacity difference using mechanical compared to the manual method. Furthermore, the results showed that the crushing machine has a sieving efficiency of not lesser than $70 \%$.
\end{abstract}

Keywords: Cocoa beans; Cocoa pod; Mechanize; Crushing machine

\section{INTRODUCTION}

The cacao tree, known for its botanical name theobroma cacao, is one of the world's popular trees growing in different parts of the planet. The fruit of the tree known as the cocoa beans can be processed to make chocolates, cocoa butter, cocoa powder, flavoring agents, etc. The husk can also be hydrolyzed to produce fermented sugar [1]. The shell is useful in producing potash fertilizer, biogas, and particle boards rich in potassium [1]. The cocoa bean is also known to be rich in fats. It contains 300 different compounds and antioxidants known to fight free radicals caused by the environment and unhealthy lifestyle [2].

According to an article published by Cidami Organization, the world market has an increasing demand for cocoa products. This information is evident because, since 1970, the global demand for cocoa has tripled. This report gave rise to the Philippines' proposed program called the "Cacao Double-up Program" [3]. As a tropical country, the Philippines have great potential in growing cacao and producing cocoa products. With all the uses and welfares in the Philippine market and agricultural sectors, the cocoa bean is considered one of the most widely consumed and highly in-demand products.

The mechanized machine for cocoa pod splitting did not widely exist either in small or big farms in the Philippines. The cacao pod splitting and bean removal in the country were merely done manually, limiting cocoa production. Thus, developing a machine that will separate the beans from the pods is necessary to improve cocoa production in the Philippines.

\section{MATERIALS}

The materials used in the fabrication of the cacao pod crushing machine are shown in tables $1 \mathrm{a}$ and $1 \mathrm{~b}$. Included in the table $1 \mathrm{a}$ and $1 \mathrm{~b}$ are the descriptions and functions of each material.

On the other hand, the cacao varieties used to test the performance of the fabricated machine include PBC 123, UF 18, W10, and BR 25.
Table 1a. Description and Functions of Materials

\begin{tabular}{l} 
Materials \\
\hline Pulley and Belt \\
Electric Motor \\
with Reduction \\
Gear
\end{tabular}

Description and Functions

Belts are used to transmit power which links two rotating shaft mostly in parallel [10]. Pulleys can be used to lift loads and transmit power [14]. mechanical energy and is commonly used in devices, fans, pumps, etc. to operate in motion [15].

Shaft

Circular in cross-section and are used to transmit power in rotating motion between the power source and the machine members that absorbs the power. These are classified into transmission shaft and machine shafts [16].

Bolts and Nuts These are used in fixing and fastening materials together. The pair moves with a greater force when either the two are turned [17].

Switch This is a device used to make and brake connection in an electric circuit or motor [18].

Blade This is a flat or wide portion of a tool that is designed to cut, puncture, chop, and slice which differs in size, length and thickness [19].

Angle Bar This is an L-shaped cross section structural steel bar which provides support to the machine and serves as the machine's skeleton [20]. 
Table 1b. Description and Functions of Materials

\begin{tabular}{|c|c|}
\hline Materials & Description and Functions \\
\hline Flat Bar & $\begin{array}{l}\text { This has many uses mainly as } \\
\text { frame, supports, bases, or trims } \\
\text { and may vary based on its } \\
\text { metallic composition and } \\
\text { purposes [21]. }\end{array}$ \\
\hline Pillow Block & $\begin{array}{l}\text { Also known as house bearing or } \\
\text { plumber block which provides } \\
\text { support for the rotating shaft } \\
\text { along with various accessories } \\
\text { and bearings [22]. }\end{array}$ \\
\hline Metal Primer & $\begin{array}{l}\text { Provides protection of metals } \\
\text { from exposure that would } \\
\text { eventually lead to rust and decay } \\
\text { of the metal and is always } \\
\text { recommended to be used [23]. }\end{array}$ \\
\hline $\begin{array}{l}\text { Sprocket and } \\
\text { Chain }\end{array}$ & $\begin{array}{l}\text { Mainly used to transmit rotary } \\
\text { motion between two shafts and } \\
\text { can be run in a low or high speed } \\
{[24] \text {. }}\end{array}$ \\
\hline Plain Bar & $\begin{array}{l}\text { Reinforcing bar which is mainly } \\
\text { used to provide support and } \\
\text { structure of a traction frame [25]. }\end{array}$ \\
\hline Plain Sheet & $\begin{array}{l}\text { Metal sheet is used in machine } \\
\text { bodies, automobile and truck } \\
\text { bodies, medical tables and or } \\
\text { roofing [26]. }\end{array}$ \\
\hline
\end{tabular}

\section{METHODS}

This chapter discussed about the design of the Cacao Pod Crushing machine, fabrication and performance evaluation.

\subsection{Machine design}

The cacao pod crushing machine was designed to have a hopper compartment for the cacao to be dumped or feed inside. The lower interior of the hopper was to be composed of two 1-inch inside diameter stainless steel cylinders with four stainless steel blades attached in each cylinder. The cutting blades was designed to have two types i.e. plain and tooth-type and must be placed in an alternate position. The tooth-type blade will push and crack the pods and the other blade will crush the pods without harming the beans.

In this manner, the cacao pod will be crushed into two or more parts. An angled plain sheet was to be situated under the rotating blades to guide the crushed cacao towards the rotating sieve. The sieve was designed to have holes to enable the beans to pass through while being pulled under gravity. Lastly, the opening end of the sieve was designed to serve as discharge point for the crushed pods.

\subsection{Fabrication and performance evaluation}

The cacao pod crushing machine was fabricated based on the formulated design. It was then evaluated to determine the crushing and sieving efficiency, and crushing capacity.

\subsubsection{Experimental set-up}

The four treatments used on the study are the four varieties of cacao namely the PBC 123, UF 18, W 10 and BR 25. The data analysis used on the study was analysis of variance (ANOVA) of complete randomized design (CRD) and the treatments were replicated three times. The treatments were then compared and analyzed based on the performance evaluation consideration.

\subsubsection{Data gathering}

Data were gathered by determining the capacity and efficiency of the machine to crush the pods and separate the beans from the rest of the crushed pods. The bean loss and damage percentage were also determined.

\subsubsection{Machine efficiency}

Machine efficiency is considered an important measure of the machine's performance to determine whether the machine is effective at all cost. The cacao pod crushing machine was measured by its crushing and sieving efficiency since the two mechanisms were involved. The machine's crushing and sieving efficiencies were computed using equations 1 and 2 .

\section{a. Machine crushing efficiency}

The crushing efficiency of the machine can be obtained through the number of cacao crushed (output) divided by the number of cacao placed in the compartment to be crush multiplied by $100 \%$ [28].

$$
\mathrm{CE}_{\mathrm{m}}=\frac{\mathrm{CC}_{\mathrm{n}}}{\mathrm{C}_{\mathrm{i}}} \times 100
$$

Where:

$$
\begin{aligned}
\mathrm{CE}_{\mathrm{m}} & =\text { Machine crushing efficiency } \\
\mathrm{CC}_{\mathrm{n}} & =\text { total number of crushed cacao } \\
\mathrm{C}_{\mathrm{i}} & =\text { Total number of cacao input }
\end{aligned}
$$

\section{b. Machine sieving efficiency}

The efficiency of the sieve to separate the beans from pods was obtained through the mass of threshed or sieved beans in $\mathrm{kg}$ (output) divided by the total mass of beans (input) multiplied by 100 [29].

$$
\mathrm{SE}_{\mathrm{m}}=\frac{\mathrm{M}_{\mathrm{tb}}}{\mathrm{M}_{\mathrm{T}}} \times 100
$$

Where:

$$
\begin{aligned}
& \mathrm{SE}_{\mathrm{m}}=\text { Machine sieving efficiency, } \% \\
& \mathrm{M}_{\mathrm{tb}}=\text { mass of threshed beans, } \mathrm{kg} . \\
& \mathrm{M}_{\mathrm{tb}}=(\text { Total mass of beans input })-(\text { mass of } \\
& \text { un-threshed beans), kg. } \\
& \mathrm{M}_{\mathrm{T}}=\text { Total mass of beans input, } \mathrm{kg} .
\end{aligned}
$$

\subsubsection{Bean loss and Damage Percentage}

Bean loss and damage percentage are important to measure to determine if the machine is efficient in separating the beans from the pods. Bean losses are those beans that are not separated from the pods but can still be recovered while bean damage are those injured beans that cannot be recovered. Since efficiency of a machine can never be greater than $100 \%$, losses can be considered as part of the machine's operation. Bean losses percentage (\%) was calculated using equation 3 [30].

$$
\mathrm{B}_{\mathrm{L}}=\frac{\mathrm{U}_{\mathrm{b}}}{\mathrm{T}_{\mathrm{m}}} \times 100
$$


Where:

$$
\begin{aligned}
& \mathrm{B}_{\mathrm{L}}=\text { Bean loss percentage, } \% \\
& \mathrm{U}_{\mathrm{b}}=\text { Mass of un-sieved beans, } \mathrm{kg} . \\
& \mathrm{T}_{\mathrm{m}}=\text { Total mass of beans, } \mathrm{kg} .
\end{aligned}
$$

On the other hand, bean damage percentage was computed using equation 4 [29].

$$
\mathrm{B}_{\mathrm{D}}=\frac{\mathrm{D}_{\mathrm{b}}}{\mathrm{T}_{\mathrm{m}}} \times 100
$$

Where:

$$
\begin{aligned}
& B_{D}=\text { Bean damage percentage, } \% \\
& D_{b}=\text { Mass of damaged beans, } k g . \\
& T_{m}=\text { Total mass of beans, } k .
\end{aligned}
$$

Total losses of beans were computed by summing up the total values of bean losses and the bean damage percentage [30].

$$
\mathrm{T}_{\mathrm{L}}=\mathrm{B}_{\mathrm{L}}+\mathrm{B}_{\mathrm{D}}
$$

Where:

$$
\begin{aligned}
& \mathrm{T}_{\mathrm{L}}=\text { Total loss, } \% \\
& \mathrm{~B}_{\mathrm{L}}=\text { Bean loss percentage, } \% \\
& \mathrm{~B}_{\mathrm{D}}=\text { Bean damage percentage, } \%
\end{aligned}
$$

\subsubsection{Machine crushing capacity}

Machine crushing capacity was computed using equation 6 [28].

$$
C C_{m}=\frac{C_{N}}{C_{T}}
$$

Where:

$$
\begin{aligned}
& \mathrm{CC}_{\mathrm{m}}=\text { Machine Crushing Capacity } \\
& \mathrm{C}_{\mathrm{N}}=\text { Total number of cacao input per unit of time. } \\
& \mathrm{C}_{\mathrm{T}}=\text { Total Operating Time }
\end{aligned}
$$

To determine the difference in capacity, the crushing capacity of the machine was compared with the manual process of cacao pod splitting.

\section{Results and Discussions}

\subsection{Machine design}

Shown in figure 1 is the perspective view of the cacao pod crushing machine. Shown also are the different parts of the machine. The cacao pod crushing machine has a hopper compartment to contain the fresh cacao pods. The lower interior of the hopper has two 1-inch inside diameter stainless steel cylinders with four stainless steel blades attached in each cylinder. The plain and tooth-type blades are placed in an alternate position.

Under the rotating blades was an angled plain sheet to guide the crushed cacao towards the sieve. The sieve has holes which separate the beans from the rest of the pods. The opening end of the sieve serves as the discharged point of the crushed pods.

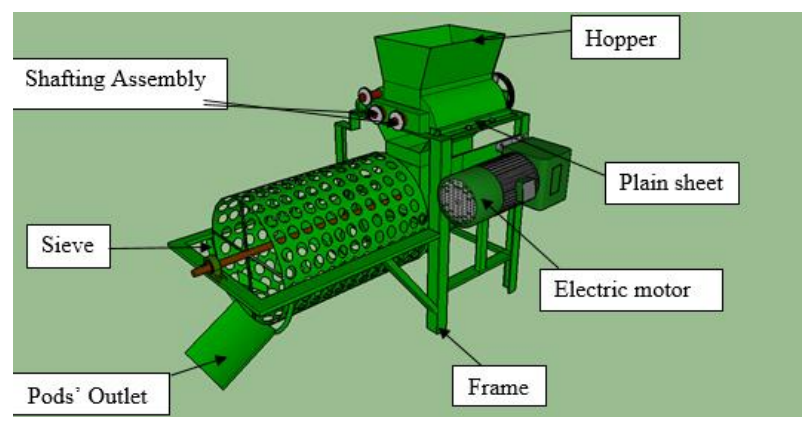

Figure 1. Perspective View of Cacao Pod Crushing Machine

\subsection{Fabrication and performance evaluation}

Figure 2 shows the actual photo of the fabricated cacao pod crushing machine. The machine was fabricated according to its specifications and functions and is suitable for small-scale cacao processing.

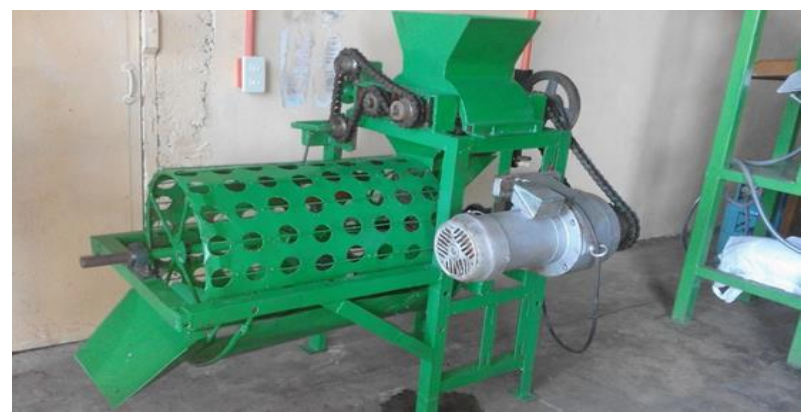

Figure 2. Cacao Pod Crushing Machine

\subsubsection{Machine efficiency}

\section{a. Machine crushing efficiency}

Table 2 shows the different observations of the machine's crushing efficiency with respect to the different varieties. The results are obtained by dividing the fruit output over the fruit input with respect to operating time. The operation was performed on the various samples in three trials. As observed, the fruit output percentage values on different varieties have a slight difference. This is because the blades of the machine were equipped with an adjuster, which does not limit the variety of cacao feed into the machine; thus, the number of crushed fruits is almost the same using the four varieties.

Table 2. Machine Crushing Efficiency on Different

\begin{tabular}{ccccc}
\multicolumn{5}{c}{ Varieties } \\
\cline { 2 - 5 } Variety & 1 & 2 & 3 & Average \\
PBC 123 & 94 & 93 & 90 & 92.3 \\
UF 18 & 83.3 & 90 & 83.3 & 86 \\
W 10 & 90 & 83.3 & 83.3 & 86 \\
BR 25 & 83.3 & 83.3 & 83.3 & 83.3 \\
\hline
\end{tabular}

To provide a more visual presentation, figure 3 illustrates the three trials used on different varieties and how they differ. As shown on the graph, the machine evaluation using the PBC 123 variety has the maximum average of crushing efficiency in percentage among the four as supported on the figure 9 of machine crushing capacity. This is because, the PBC 123 variety as previously illustrated on table 2, has the slenderest body among the 
four varieties. On the other hand, using the BR 25 variety has the least value of crushing efficiency since it has a relatively round and big size.

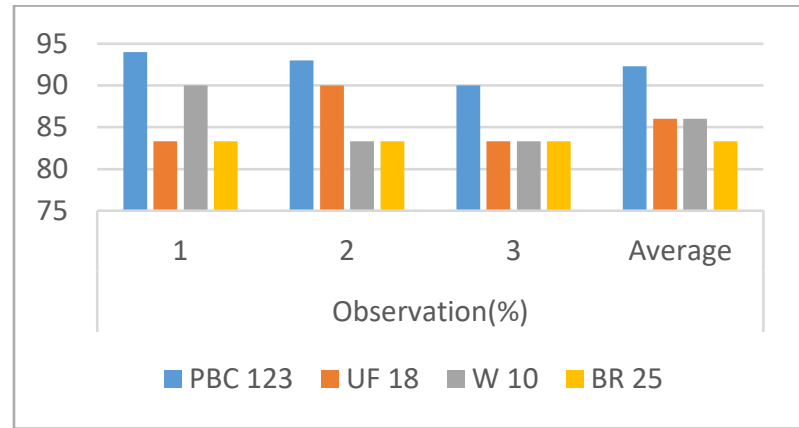

Figure 3. Graphical Representation of Machine's Crushing Efficiency Percentage

b. Machine sieving efficiency

In table 3, observations on machine sieving efficiency on different varieties are shown. Sieving efficiency of the machine was determined by dividing the bean output with the bean input. Bean input is the mass of beans that has passed through the sieve while being separated from the placenta. Moreover, in this operation due to the commodity's bean wet state, relatively small sized beans are more likely prone to losses since they are attached at the placenta and cannot be detached easily unless the machine can produced higher vibration. The mass of bean losses in each variety was then computed and multiplied to the number of split fruit of each variety that passed through the sieve. The corresponding mass of beans in each variety of fruit was multiplied to the number of fruit that entered the sieve minus the mass of bean losses of each variety that was measured. The values are illustrated in table 3. As observed, using BR 25 variety has the maximum number of beans which indicated that it has the least number of bean loss since it has the biggest bean size among the four varieties.

Table 3. Machine Sieving Efficiency on Different Varieties

\begin{tabular}{ccccc}
\hline \multirow{2}{*}{ Variety } & \multicolumn{4}{c}{ Observation (\%) } \\
\cline { 2 - 5 } PBC 123 & 1 & 2 & 3 & Average \\
UF 18 & 90 & 95 & 92 & 92.33 \\
W 10 & 93 & 88.2 & 93 & 90.4 \\
BR 25 & 96 & 98 & 91.1 & 93.4 \\
\hline
\end{tabular}

Figure 4 shows the graphical representation of the machine's sieving efficiency on different varieties of beans. As observed, using BR 25 variety has the maximum percentage among the treatments. It was because the variety has relatively large beans. Furthermore, the results showed that the machine was efficient on the three varieties in which the percentage of efficiency was not lesser than $70 \%$.

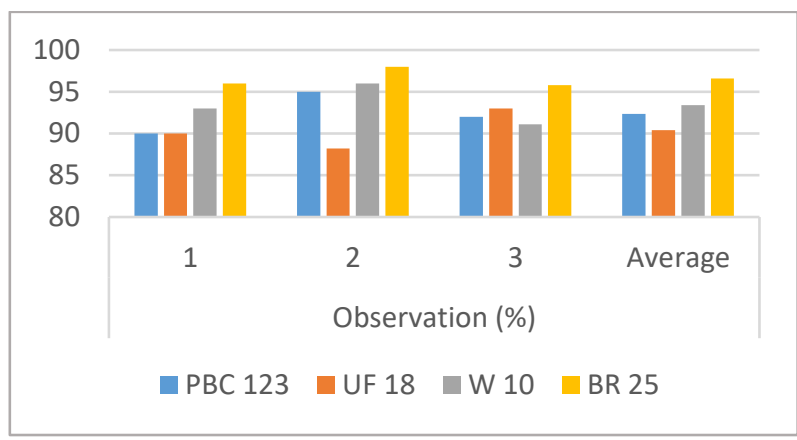

Figure 4. Graphical Representation of Machine Sieving Efficiency

\subsubsection{Bean loss and damage percentage}

Table 4 illustrates the percentage representation of bean losses during operation on different varieties. Bean loss percentage was obtained by the mass of bean loss divided by the total mass of bean input and multiplied by 100 . As observed in the table, using PBC 123 variety has the maximum percentage of bean loss among the four treatments. This is because PBC 123 samples are relatively small in size with small bean sizes and more prone to losses.

On the other hand, BR 25 beans are the least prone among the four varieties since it has larger beans. Although there are losses in the sieving operation of beans, it can still be recovered because most the beans that contributed to losses went together with the pods but are not injured.

Table 4. Percentage Representation of Bean Losses during operation

\begin{tabular}{ccccc}
\hline Variety & \multicolumn{4}{c}{ Bean Losses (\%) } \\
\cline { 2 - 5 } PBC 123 & 1 & 2 & 3 & Average \\
UF 18 & 12.79 & 15.00 & 7.69 & 12.8 \\
W 10 & 6.82 & 10.00 & 13.16 & 11.8 \\
BR 25 & 6.00 & 4.17 & 8.70 & 11.90 \\
\hline
\end{tabular}

Figure 5 represents the graphical percentage of bean loss on different trials conducted in each variety. As observed on the graph, among the three trials, using variety 4 which is BR 25 obtained the lowest bean loss percentage as also shown in the preceding table.

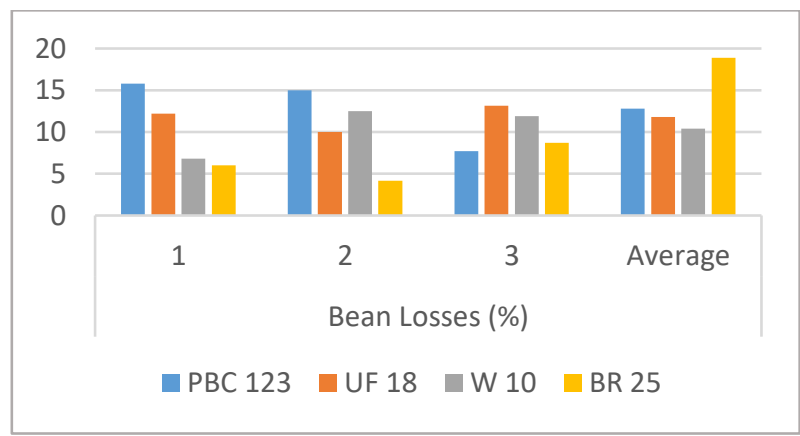

Figure 5. Graphical Representation of Bean Loss Percentage

On the other hand, as shown on figure 6 which is the graphical representation of bean damage percentage, using BR 25 has the highest bean damage percentage contrasting the result from the bean loss percentage. This is because the latter has the relatively large sized beans among the four varieties which is more prone to injury 
during operation. On the other hand, using variety 1 (PBC 123) and variety 2 (W 10) has the least bean damage percentage. Although there are losses, bean damage cannot be recovered since the beans are injured inside but these cases are very rare to happen.

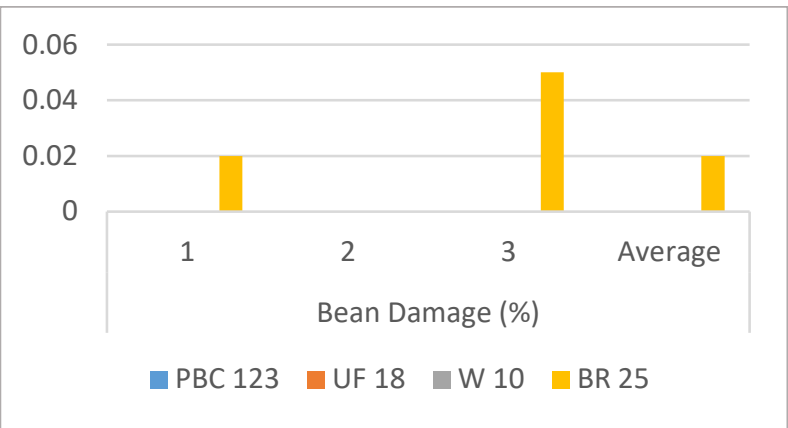

Figure 6. Graphical Presentation of Bean Damage Percentage

\subsubsection{Total losses}

Figure 7 shows the graphical representation of total losses in percentage of beans in each variety. Total losses percentage was obtained by adding the bean loss and the bean damage percentage. As observed, there has no changed in the percentage value of the variety from which the values were the same in bean loss percentage. This is because there has no bean damage obtained from the three varieties. Only the fourth variety has recorded bean damage in which the observation 3 in the graph increased a bit.

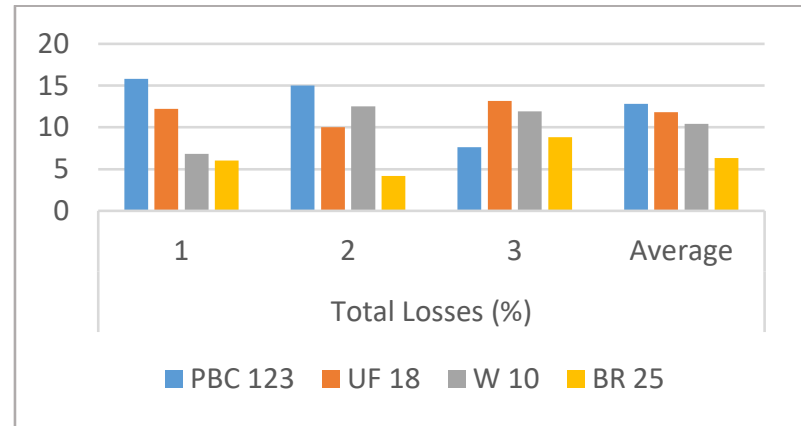

Figure 7. Graphical Representation of Total Losses Percentage

Figure 8 shows the graphical representation of total bean losses recovery in percentage. Total bean loss recovery was obtained by bean loss percentage in each variety divided by Total Bean Loss multiplied by 100 . As observed on the graph, the percentage recovery of the three varieties was $100 \%$ since there has no bean damage recorded. On the other hand, variety four recorded bean damages that it has the least percentage recovery among the four varieties.

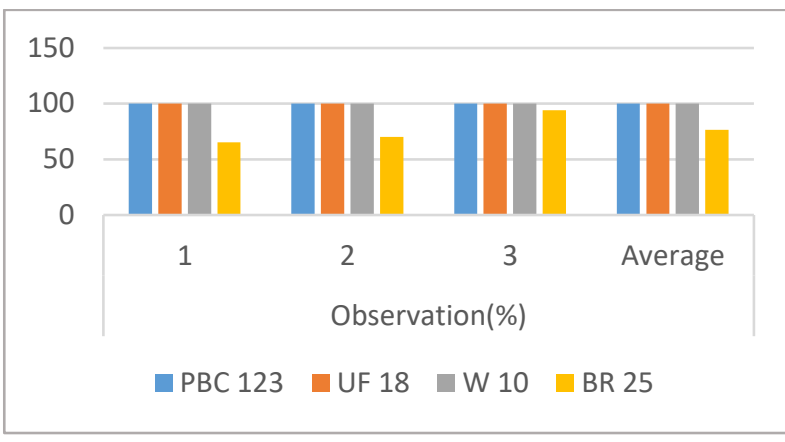

Figure 8. Graphical Representation of Total Bean Loss Recovery

\subsubsection{Machine crushing capacity}

Shown on table 5 are the observations on the machine crushing capacity (fruit/hour) with three trials for each variety. The table shows that the number of fruit that can be crushed was directly proportional with the size of fruit. This was evident since using PBC 123 which has the slenderest size among the four varieties got the maximum average of crushing capacity. While, using the variety BR 25 which has the roundest size, has the minimum average of crushing capacity. The following two varieties, UF 18 and W 10 which are almost similar in size, obtained the same average of crushing capacity per hour.

Table 5. Machine Crushing Capacity on Different Varieties

\begin{tabular}{ccccc}
\hline Variety & \multicolumn{4}{c}{ Observation (fruit/hour) } \\
\cline { 2 - 5 } PBC 123 & 1 & 2 & 3 & Average \\
UF 18 & 1020 & 1140 & 900 & 1040 \\
W 10 & 1020 & 1020 & 900 & 980 \\
BR 25 & 960 & 960 & 900 & 980 \\
& &
\end{tabular}

Figure 9 illustrates the differences of replication in each variety in determining the machine's crushing capacity (fruit/hour). As observed, trial 1 and 2 on four varieties differ, this is because the samples taken vary in size. Consequently, in trial 3, samples are at the same size which obtained almost similar results.

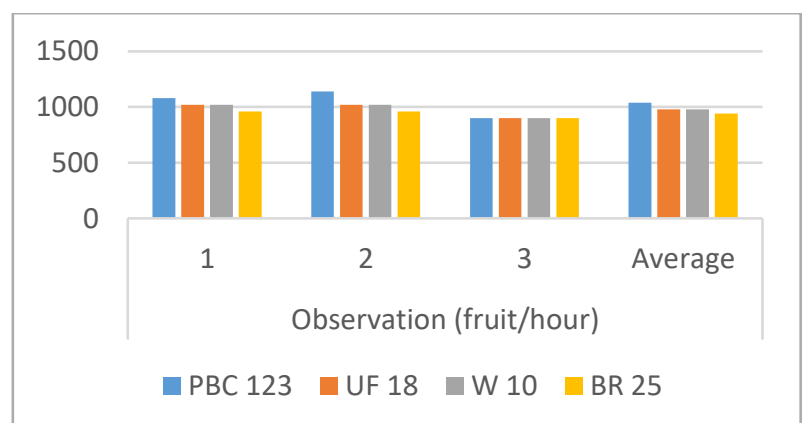

Figure 9. Graphical Representation of Machine Crushing Capacity on Different Varieties

ANOVA of Machine Crushing Capacity in table 6 showed non-significant differences of the capacity of crushing with respect to four different treatments which are the four varieties. The computed f, 0.77 is smaller than the critical $\mathrm{f}$ at $5 \%$ level which means that the experiment was not able or did not detect any significant differences on the four treatments or varieties used. Thus, 
the result of the ANOVA implies that the capacity of the machine does not vary with respect to the variety of cacao.

Table 6. ANOVA of Machine Crushing Capacity

\begin{tabular}{cccccccc}
\hline $\begin{array}{c}\text { Source of } \\
\text { Variation }\end{array}$ & SS & Df & MS & F & $\begin{array}{c}\text { P- } \\
\text { value }\end{array}$ & \multicolumn{2}{c}{$\mathbf{F}$ critical } \\
\hline Treatment & 153 & 3 & 510 & 0.7727 & 0.5410 & 4.066 & 7.59 \\
Error & 528 & 8 & 660 & & & & \\
& & & & & & & \\
Total & 681 & 11 & & & & & \\
\hline 'cv=5.47\% \% & & & & & \\
Non-significant
\end{tabular}

Table 7 shows the comparison of results in performance capacity in crushing cacao pods obtained from the two methods, manual and mechanical. Based on the results, mechanical method has higher capacity of crushing cacao pods than the manual method with an average of 1000 fruits per hour using the cacao pod crushing machine compared to 660 fruits per hour of manual pod splitting.

Table 7. Performance Capacity Comparison in Crushing Cacao

\begin{tabular}{ccccc}
\hline Method & \multicolumn{2}{c}{ Observation (fruit/hour) } & Average \\
\cline { 2 - 4 } & 1 & 2 & 3 & \\
Manual & 660 & 540 & 780 & 660 \\
Mechanical & 1020 & 1080 & 900 & 1000 \\
\hline
\end{tabular}

Shown in table 8 is the result of T-test performed to determine the level of difference between the crushing capacities of the two methods. The t-test indicates significant differences in crushing capacity between the two methods at $5 \%$ level of significance. The p-value computed which is 0.018 is less than 0.05 , thus there is a significant difference between manual and mechanical method.

Table 8. T-test of Significant Difference between the Two Methods

\begin{tabular}{lllr}
\hline & Manual & \multicolumn{1}{c}{ Mechanical } \\
\hline Mean & 660 & 1000 \\
Variance & 14400 & 8400 & \\
P-Value & & \multicolumn{2}{c}{0.018} \\
Interpretation & & *Significant @ 5\% level \\
\hline
\end{tabular}

\section{CONCLUSION}

Based on the data gathered and the results obtained during evaluation, the cacao pod crushing machine can be considered more efficient in crushing pods and separating cacao beans since the performance capacity comparison favored the mechanical method. These results were supported by determining the variation in crushing capacity. The results implied a significant difference in the crushing capacity performance of the machine compared to the manual method. In which in 1 hour operation, the average maximum number of split fruit using the machine was 1000 fruits, while in the manual process, there were only 660 fruits.

\section{REFERENCES}

[1] S.K. Adzimah and E.K. Asiam, Design of Cocoa Pod Splitting Machine, Department of Engineering, Faculty of Engineering, Department of Mineral Engineering, Faculty of Mineral Resources and Technology, University of Mines and Technology, Ghana, 2010

[2] foodfacts.mercola.com/cacao.html

[3] www.cidami.org/philippines-2020-challenge/

[4] https://en.wikipedia.org/wiki/theobroma_cacao

[5] https://www.icco.org/fag/61-physical-and-chemicalinformation-on-cocoa/106-physical-and-chemicalinformation-on-cocoa-beans-butter-masspowder.html

[6]http://www.dailymail.co.uk/sciencetech/article3312187/Cocoa-10m-years-OLDER-thoughtpossibly-leading-new-flavours.html

[7] http://www.indiatimes.com/health/buzz/healthbenefits-of-cocoa-beans-242096.html

[8] https://www.cadbury.com.au/aboutchocolate/harvesting-and-process-cocoa-beans.aspx

[9] www.cacaoweb.net/cacao-tree.html

[10] mrdp.da.gov.ph/elearning/cacao/index.html

[11]www.sunstar.com.ph/davao/business/2015/11/08/m alagos-chocolate-proudly-davao-made-440405

[12] http://www.yvesrocher.ca/control/category/ categor y_id=CC03/

[13] PRDP, Value Chain Analysis and Competitiveness Strategy: COCOA BEAN Mindanao, 2014.

[14] https://en.wikipedia.org/wiki/belt_(mechanical)

[15] https://en.wikipedia.org/wiki/Electric_motor

[16]http://en.wikipedia.org/wiki/Shaft_(Mechanical_En gineering)

[17] www.freedictionary.com/nut+and+bolt

[18] https://en.oxforddictionaries.com/definition/switch

[19] https://en.wikipedia.org/wiki/Blade

[20] http://www.dictionary.com/browse/angle-bar

[21] https://www.metalsdepot.com/shapes/flat-bar/

[22]https://en.m.wikipedia.org/wiki/Pillow_block_beari ng

[23]www.doityourself.com/stry/metal-paint-primerwhen-is-it-neccesary

[24] https://en.wikipedia.org/wiki/Sprocket

[25]http://www.mizuhosi.com/products/over-bedtraction/traction-components-accessories/plain-bars/

[26] https://en.wikipedia.org/wiki/Sheet_metal

[27]www.physicsclassroom.com/class/energy/Lesson$1 /$ Power

[28]http://bilingualonline.net/contents/Turabo/MANA7 05/week_8/8_6.html

[29]PAES 205:2000, “Agricultural MachineryMechanical Rice Thresher-Methods of Test, pp.22

[30]A.K. Zaalouk, "Evaluation of Local Machine Performance for Threshing Bean", Agricultural Engineering Department, Faculty of Agriculture, AlAzhar University, 2009.

[31] M. Arreola, "Third Edition Engineering Economy". 